\title{
Modeling CFC inventories and formation rates of Labrador Sea Water
}

\author{
C. W. Böning, ${ }^{1}$ M. Rhein, ${ }^{2}$ J. Dengg, ${ }^{1}$ and C. Dorow ${ }^{1}$ \\ Received 4 February 2002; accepted 16 April 2002; published 22 January 2003.
}

[1] A high-resolution model of the North Atlantic Ocean is used to examine the potential of chlorofluorocarbon (CFC) inventories for calculating the rate of Labrador Sea Water (LSW) formation. While the simulated CFC-11 inventory and its geographical distribution in 1997 is fairly similar to observations, the model indicates pronounced variations in the history of CFC uptake, reflecting pulsations in LSW renewal in response to changes in wintertime atmospheric conditions. The LSW formation rate based on the volume of newly homogenized water during a winter season varies between $0 \mathrm{~Sv}$ and $11 \mathrm{~Sv}$, and it is correlated (with a lag of 1 year) with the North Atlantic Oscillation (NAO) Index. The CFC-based estimate of the mean LSW formation rate is 3.54.4 Sv, approximately representing the mean volumetric formation rate $(4.3 \mathrm{~Sv})$ for the period $1970-1997$. INDEX TERMS: 4875 Oceanography: Biological and Chemical: Trace elements; 4536 Oceanography: Physical: Hydrography; 4215 Oceanography: General: Climate and interannual variability (3309); 4255 Oceanography: General: Numerical modeling; 4283 Oceanography: General: Water masses. Citation: Böning, C. W., M. Rhein, J. Dengg, and C. Dorow, Modeling CFC inventories and formation rates of Labrador Sea Water, Geophys. Res. Lett., 30(2), 1050, doi:10.1029/2002GL014855, 2003.

\section{Introduction}

[2] As the primary source of the upper part of the North Atlantic Deep Water (NADW), Labrador Sea Water (LSW) is an important component of the global meridional overturning circulation (MOC). It is formed in the central Labrador Sea (LS) by vigorous, deep-reaching convective processes following periods of extensive heat loss in late winter [Marshall and Schott, 1999] which, in some years, homogenize the water column well below $2000 \mathrm{~m}$ depth [Lab Sea Group, 1998]. Determining the causes and effects of variations in the extent of LSW formation is an important task in ocean climate studies: particular issues are the relation between the annual renewal rate and changes in atmospheric conditions associated, e.g., with the NAO [Dickson et al., 1996], and the link to variations in the MOC and thus in the meridional oceanic heat transport suggested by model studies [Häkkinen, 1999; Eden and Willebrand, 2001].

[3] While long-term hydrographic records from the LS demonstrate striking changes in LSW properties over the last century [Lazier, 1988; Dickson et al., 1996; Curry et al., 1998], there is only fragmentary knowledge of the LSW

\footnotetext{
${ }^{1}$ Institut für Meereskunde, Universität Kiel, Kiel, Germany.

${ }^{2}$ Institut für Umweltphysik, Universität Bremen, Bremen, Germany.
}

Copyright 2003 by the American Geophysical Union. 0094-8276/03/2002GL014855 formation rate, its variability, and its quantitative contribution to the MOC transport. Direct calculation of annual LSW formation rates, i.e., of the volume of newly ventilated water during a winter season has only been possible for exceptional years with sufficient hydrographic data coverage; the classical example is Clarke and Gascard [1983]. Indirect estimates, of mean formation rates for different periods, have been obtained from considerations of climatological heat budgets [McCartney and Talley, 1984] and surface buoyancy fluxes [Speer and Tziperman, 1992]. Using annual climatologies of heat and freshwater fluxes over 1980-1997, Marsh [2000] inferred a quasi-decadal variation in LSW production between near zero in the early 1980s and a maximum of about $10 \mathrm{~Sv}$ in 1990 , returning to near zero by 1997.

[4] An alternative approach for calculation of mean LSW production, the use of chlorofluorocarbon (CFC) measurements, was proposed in recent studies by Smethie and Fine [2001] (hereafter, SF01) and Rhein et al. [2002] (R02). CFCs enter the ocean at the surface and get incorporated in LSW during convection.

[5] From estimates of the CFC inventory for the subpolar North Atlantic north of $40^{\circ} \mathrm{N}$ (NA) during 1997, R02 calculated a mean formation rate of 4.4-5.6 Sv, while SF01 obtained 7.4 Sv, using composite data from 19861992 from the whole North Atlantic, and assuming different CFC surface boundary conditions in the convection area. An issue germane to both studies is the sparseness of historical CFC-data coverage and thus information on the time history of CFC uptake due to interannual variability of LSW renewal. How is the CFC uptake linked to the varying, convective renewal of LSW and to which degree does the CFC-based estimate of the LSW formation rate correspond to the "classical", volumetric estimate? These issues are elucidated by an ocean circulation model which simulates the temporal evolution of CFC uptake in the Atlantic Ocean.

\section{The Model}

[6] The model is based on a refined configuration of the Modular Ocean Model (MOM2.1) [Pacanowski, 1995], developed as part of a hierarchy of Atlantic Ocean models ("FLAME"; e.g., Dengg et al. [1999]). The model version adopted here uses a similar horizontal grid $\left(1 / 3^{\circ}\right.$ by $1 / 3^{\circ} \cos$ $(\phi)$ ) and domain (from $18^{\circ} \mathrm{S}$ to $70^{\circ} \mathrm{N}$ ) as the DYNAMO model intercomparison study [Willebrand et al., 2001]; a higher vertical resolution (45 levels), adaptation of a bottom boundary layer scheme, and lateral subgrid scale mixing along isopycnals have led to improvements especially with respect to deep water formation and meridional overturning [Dengg et al., 1999; Redler and Dengg, 1999]. Atmospheric forcing is by the same ECMWF-based monthly mean fluxes 
as in DYNAMO, but has superimposed heat flux anomalies for 1959-1997 from NCEP-NCAR reanalyses products [Kalnay et al., 1996]. As discussed for a coarser $\left(4 / 3^{\circ}\right)$ version of the present model, the ocean response includes interannual variations in LS convection over a depth range of about $1000 \mathrm{~m}$ [Eden and Willebrand, 2001]. Using the T-S characteristics of the water in the LS, the model analogue of LSW is defined by the density range $\sigma_{\theta}=$ 27.84-27.89, compared to $\sigma_{\theta}=27.74-27.80$ as in R02.

[7] The model went through a spin-up of 15 years, during which the amplitude of the MOC adjusted to a maximum of about $18 \mathrm{~Sv}$. By this time, trends in the MOC were generally smaller than the interannual-to-decadal oscillations driven by the atmospheric variability; see also Eden and Willebrand [2001]. Starting from this spun-up state, the uptake of CFC-11 was simulated for 1959-1997. Gas exchange at the surface was set proportional to the difference between the surface concentration and the saturation concentration, given as a function of solubility and atmospheric concentration following Warner and Weiss [1985]. The proportionality coefficient, or "piston velocity", was taken as a constant, equivalent to a time scale of 1.0 day, at which the concentration in the $10 \mathrm{~m}$-surface layer relaxes to the saturation value. Sensitivity runs (see also Beismann and Redler [2003]) showed the main effect of this parameter to be on the drop in saturation during phases of active convection in the LS: with the present choice the model gives a CFC concentration of about $60 \%$ saturation in the LSW formation region, similar to observational estimates [Wallace and Lazier, 1988; Smethie et al., 2000].

\section{Results}

[8] The CFC concentrations for 1997 (Figure 1) are suggestive of the three major pathways for LSW, originally described by Talley and McCartney [1982] based on hydrographic properties: from its formation region in the LS, branches with relatively high concentration of CFC extend to the northeast into the Irminger Sea (IS), into the eastern basin between $50^{\circ}$ and $55^{\circ} \mathrm{N}$, and to the southwest along the Grand Banks of Newfoundland. The overall distribution of R02 is fairly well simulated, but there are some regional model deficiencies, especially in the eastern basin: while the eastward branch of LSW appears less prominent in the model, wedges of high CFC concentrations extend southwestward along the Reykjanes Ridge and in Rockall Trough. The latter are signatures of CFC-bearing overflow water from the Norwegian Sea, turning up in the LSW budget as an effect of the higher LSW density range in the model, which implies less distinction between the densities of the LSW and the overflow across the Iceland-Scotland Ridge.

[9] From the measurements in 1997, R02 calculated a total CFC-11 inventory of $16.6 \pm 1.7$ million moles of CFC11 in the LSW between $40^{\circ}$ and $65^{\circ} \mathrm{N}$. The model inventory is 15.7 million moles, of which, however, 2.7 million moles $(17 \%)$ are attributable to the overflow. Table 1 summarizes the model CFC-flux out of the LS by comparing regional inventories to observations (R02). While the pathway into the IS is quantitatively realistic (19\% vs. $20 \%$ of the subpolar CFC-inventory), the supply of the eastern basin is too weak: in the model, only $24 \%$ of the total subpolar
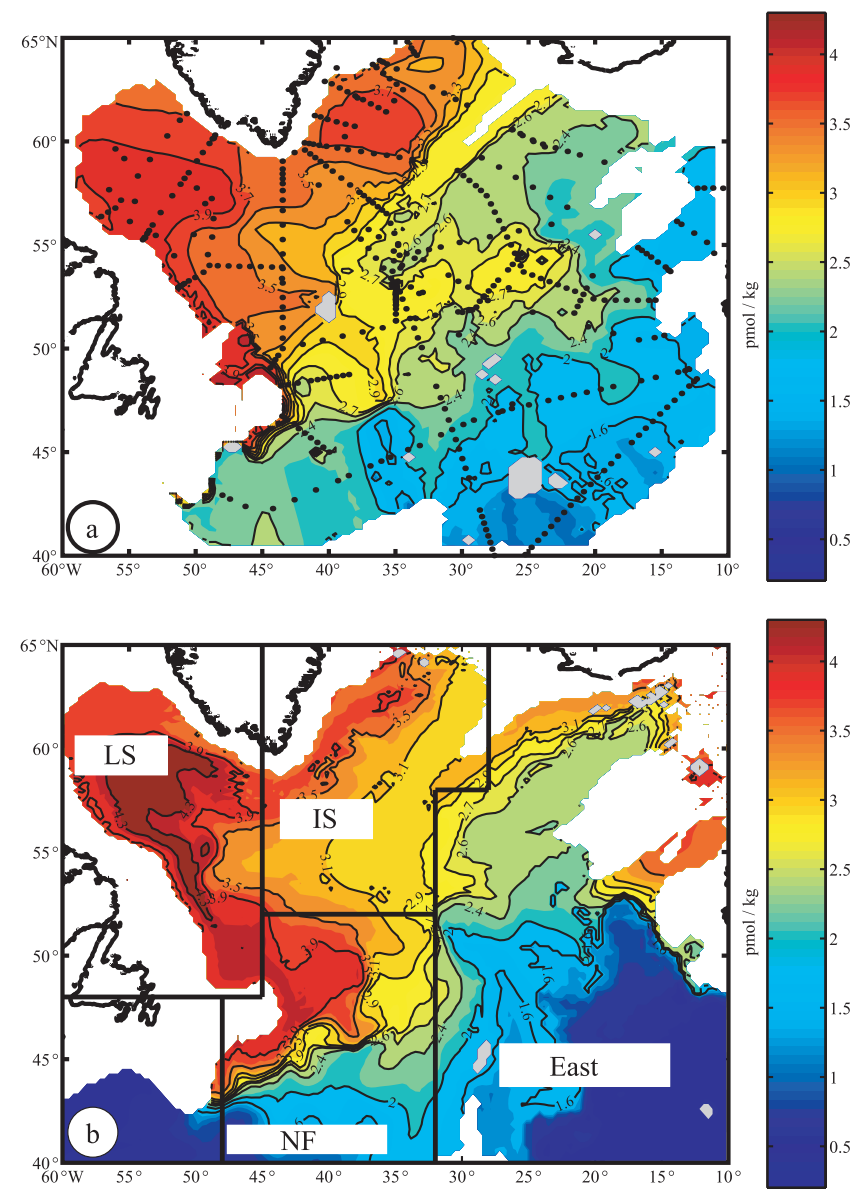

Figure 1. Mean CFC-11 distribution [pmol/kg] in the LSW layer for 1997, (a) from observations (R02) and (b) from the model. The black lines indicate the box boundaries for the inventory calculations of Table 1 .

CFC-inventory are found here, vs. $31 \%$ in the observations. Moreover, about $2 / 3$ of the eastern inventory are due to the overflow contribution. This is probably attributable to a stronger blocking of the eastward penetration of LSW by the Mid-Atlantic Ridge, since the denser model LSW spreads at about 300-400 m greater depths than observed. The lack of export to the eastern basin is reflected by a higher than observed inventory in NF (32\% vs. $21 \%$ ). Despite this regional distortion, the net export of LSW from the subpolar North Atlantic is captured realistically: the 1990 -inventory for the Atlantic proper south of $42^{\circ} \mathrm{N}$ is $16 \%$, close to the estimate $(18 \%)$ of SF01. The exported fraction increases in the $1990 \mathrm{~s}$, to $22.3 \%$ in 1997.

[10] Time series of the CFC content in LSW show a nearexponential rise, with a more pronounced increase in 1977 , 1984/1985 and 1990-93. The annual uptake anomalies, i.e., deviations from a purely exponential increase in the various basins (Figure 2), appear most pronounced in the LS and IS; their correlation (r) is highest $(0.77)$ for zero time lag, suggestive of a spreading of newly formed LSW into the IS within a few months, comparable to observations [Sy et al., 1997]. Tracer spreading to the Newfoundland Basin (NF) takes about 2 years ( $\mathrm{r}$ is $0.61,0.66,0.48$ for lags of 1 , 2,3 yrs). There is less coherence with the eastern basin, corresponding to the restricted LSW flow across the Mid- 
Table 1. Regional Distribution of CFC-11 in 1997, in percent of the Total Inventory for the LSW Layer Between $40^{\circ}$ and $65^{\circ} \mathrm{N}$, Compared to the Observations of R02

\begin{tabular}{lcc}
\hline & Obs & Model \\
\hline LS & 28 & 25 \\
IS & 20 & 19 \\
NF & 21 & 32 \\
East & 31 & 24 \\
\hline
\end{tabular}

Atlantic Ridge. The CFC uptake anomalies are linked to changes in the convection intensity in the LS (for a discussion of the variations in winter mixed layer depths we refer to Eden and Willebrand [2001]), which correspond to changes in the thickness of the LSW layer: maximum thicknesses in the LS are obtained in 1977 and 1990, similar to observations [Curry et al., 1998]; another, weaker maximum (not apparent in the observations) occurs in the mid80 s, similar to the periods of enhanced CFC uptake in the LS.

[11] The model offers the opportunity to directly compare the CFC-based estimation of LSW renewal against the classical, volumetric calculation. Figure 3 shows the strong variability of this metric, between zero in 1970 and $11 \mathrm{~Sv}$ in the early 1990s. A qualitatively similar variation is obtained by calculating, in each year, the volume of water which was in surface contact during the previous winter (this is facilitated in the model by carrying a tracer for the "age" of the water, i.e., the time elapsed since the last surface contact, and calculating the volume of water which, in spring, is less than 0.6 years old). In some periods, this total ventilated volume is higher than the increase in LSW

CFC-11 [mol] $\times 10^{5}$
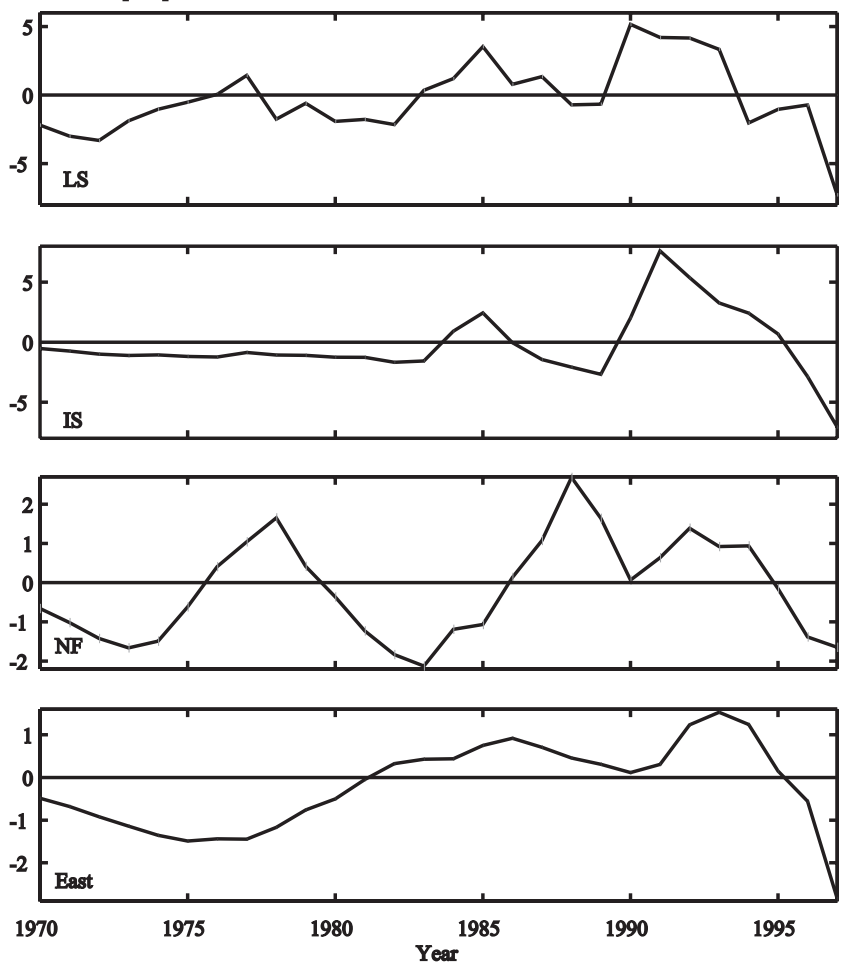

Figure 2. Time series of CFC uptake anomalies, relative to an exponential increase, for the subpolar basins.
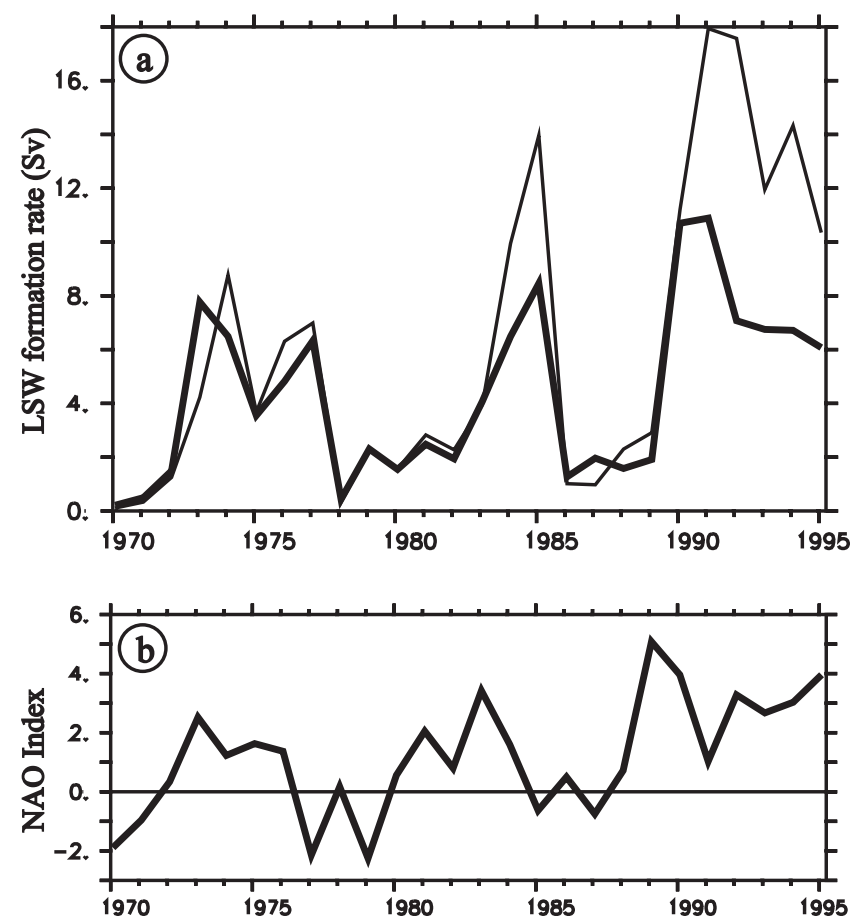

Figure 3. (a) Time series of LSW formation rates in the model, defined by the volume of newly formed LSW in winter, and (thin line) ventilation rates, defined by the total volume of water in the LS that was in surface contact during the previous winter. (b) Index of the NAO based on the difference of normalized sea level pressure between Portugal and Iceland following Hurrell [1995].

volume; in particular, after the onset of intense deep convection in 1990, the convective intensity continued to increase over the next 1-2 years, in contrast to the volume of newly formed LSW: it appears that after a few years of strong renewal only small volumes of less dense waters are left to be transformed to LSW. In spite of this preconditioning effect there is an intimate relation between LSW renewal and the atmospheric forcing variability over the subpolar NA, as represented by the NAO index (Figure $3 b$ ): for a lag of 1 year, NAO index leading, the time series are significantly correlated at the $99 \%$ level $(r=0.66$ for the original time series; $r=0.58$ after removal of the multi-year trends present in both).

[12] According to the volumetric measure, the model's mean LSW formation rate during $1970-1997$ is $4.3 \mathrm{~Sv}$. Applying the method of R02 to the simulated CFC inventory of LS origin in the model (13.0 million moles, instead of 16.6 million moles in the data), results in a CFC-based estimate of 3.4-4.4 Sv (relative to $4.4-5.6 \mathrm{~Sv}$ in $\mathrm{R} 02$ ).

\section{Conclusions}

[13] While previous, coarse-resolution model studies of CFC uptake generally noted severe problems in representing the North Atlantic deep water masses [England and Maier-Reimer, 2001], the major aspects of the observed CFC uptake in the LSW layer appear well reproduced in the present simulation; it thus constitutes a useful means to elucidate issues in LSW formation and CFC uptake that 
cannot be addressed by observations alone. Forced with atmospheric fluxes from reanalyses, the model simulates an interannual variability in LS convection [Eden and Willebrand, 2001] that has direct consequences for the renewal of LSW: pulses of enhanced formation rates, up to a maximum of $11 \mathrm{~Sv}$ in the early 1990 s, are interspersed with periods of vanishing renewal. The effect of this intermittency in LSW renewal is manifested in the simulated time series of CFC inventories, with a pronounced modulation of the basically exponential increase in uptake.

[14] Following the method of R02, the model's equivalent CFC-based estimate of the LSW formation rate is 3.44.4 Sv, basically in agreement with its mean (1970-1997) volumetric formation rate of $4.3 \mathrm{~Sv}$. This result generally encourages the use of CFC based estimates of deep water formation rates, not only for the LSW but also for other deep water masses.

[15] An issue affecting the CFC-based estimation in the observations is the export of CFC-laden LSW from the subpolar basin. The model gives a similar value (16\%) for the exported fraction as SF01 for 1990, and a somewhat higher value $(22 \%)$ for 1997 . Accounting for this exported fraction would raise the R02-estimate of the mean LSW formation rate to $5.7-7.2 \mathrm{~Sv}$.

[16] An issue requiring further study is the somewhat lower (by about 20\%) than observed inventory of CFC in the model LSW. While a systematic examination of the factors relevant to CFC-uptake in eddy-permitting models has yet to be performed, results from a companion sensitivity study with a coarser version of the present model [Beismann and Redler, 2003] suggest a dependency primarily on the parameterization of subgrid-scale physics rather than on details of the air-sea gas exchange. Further investigation of these issues will greatly benefit from the availability of basin-scale tracer inventories based on WOCE data sets.

[17] Acknowledgments. The computations were done at ZIB Berlin. Financial support was granted by the DFG through SFB 460.

\section{References}

Beismann, J.-O., and R. Redler, Model simulations of CFC uptake in the Atlantic Ocean: Effects of parameterizations and grid resolution, J. Geophys. Res., in press, 2003.

Clarke, R. A., and J.-C. Gascard, The formation of Labrador Sea Water. Part I: Large-scale processes, J. Phys. Oceanogr., 13, 1764-1778, 1983.

Curry, R. G., M. S. McCartney, and T. M. Joyce, Oceanic transport of subpolar climate signals to mid-depth subtropical waters, Nature, 391, 575-577, 1998.

Dengg, J., C. Böning, U. Ernst, R. Redler, and A. Beckmann, Effects of an improved model representation of overflow water on the Subpolar North Atlantic, International WOCE Newsletter, 37, 10-15, 1999.
Dickson, R. R., J. Lazier, J. Meincke, P. Rhines, and J. Swift, Long-term coordinated changes in the convective activity of the North Atlantic, Prog. Oceanog., 38, 241-295, 1996.

Eden, C., and J. Willebrand, Mechanism of interannual to decadal variability of the North Atlantic circulation, J. Climate, 14, 2266-2280, 2001.

England, M., and E. Maier-Reimer, Using chemical tracers to assess ocean models, Rev. Geophys., 39, 29-70, 2001.

Häkkinen, S., Variability of the simulated meridional heat transport in the North Atlantic for the period 1951-1993, J. Geophys. Res., 104, 10,991-11,007, 1999.

Hurrell, J. W., Decadal trends in the North Atlantic Oscillation: Regional temperatures and precipitation, Science, 269, 676-679, 1995.

Kalnay, E., et al., The NCEP 40-year reanalysis project, Bull. Am. Meteorol. Soc., 77, 437-471, 1996.

Lab Sea Group, The Labrador Sea deep convection experiment, Bull. Americ. Met. Soc., 79(10), 2033-2058, 1998.

Lazier, J. R. N., Temperature and salinity changes in the deep Labrador Sea, 1962-1986, Deep Sea Res., 35, 1247-1253, 1988.

Marsh, R., Recent variability of the North Atlantic thermohaline circulation inferred from surface heat and freshwater fluxes, J. Climate, 13, 32393260, 2000.

Marshall, J., and F. Schott, Open-ocean convection: Observations, theory, and models, Rev. Geophys., 37, 1-64, 1999.

McCartney, M. S., and L. D. Talley, Warm-to-cold water conversion in the northern North Atlantic ocean, J. Phys. Oceanogr., 14, 922-935, 1984.

Pacanowski, R. C., MOM 2 Documentation, User's Guide and Reference Manual, Tech. Rep. 3, GFDL Ocean Group, 1995.

Redler, R., and J. Dengg, Spreading of CFCs in numerical models of differing resolution, International WOCE Newsletter, 35, 12-14, 1999.

Rhein, M., J. Fischer, W. M. Smethie Jr., D. Smythe-Wright, R. F. Weiss, C. Mertens, D. H. Min, U. Fleischmann, and A. Putzka, Labrador Sea Water: Pathways, CFC-inventory and formation rates, J. Phys. Oceanogr., 32, 648-665, 2002.

Smethie, W. M., Jr., and R. A. Fine, Rates of North Atlantic Deep Water formation calculated from chlorofluorocarbon inventories, Deep Sea Res., 48, 189-215, 2001.

Smethie, W. M., Jr., R. A. Fine, A. Putzka, and E. P. Jones, Tracing the flow of North Atlantic Deep Water using chlorofluorocarbons, J. Geophys. Res., 105, 14,297-14,323, 2000.

Speer, K. G., and E. Tziperman, Rates of water mass formation in the North Atlantic Ocean, J. Phys. Oceanogr., 22, 93-104, 1992.

Sy, A., M. Rhein, J. R. N. Lazier, K. P. Koltermann, J. Meincke, A. Putzka, and M. Bersch, Surprinsingly rapid spreading of newly formed intermediate waters across the North Atlantic Ocean, Nature, 386, 675-679, 1997.

Talley, L. D., and M. S. McCartney, Distribution and circulation of Labrador Sea Water, J. Phys. Oceanogr., 12, 1189-1205, 1982.

Wallace, D. W. R., and J. R. N. Lazier, Anthropogenic chlorofluorocarbons in newly formed deep water, Nature, 332, 61-63, 1988.

Warner, M. J., and R. F. Weiss, Solubilities of chlorofluorocarbons 11 and 12 in water and seawater, Deep Sea Res., 32, 1470-1493, 1985.

Willebrand, J., B. Barnier, C. Böning, C. Dieterich, P. D. Killworth, C. LeProvost, Y. Jia, J.-M. Molines, and A. L. New, Circulation characteristics in three eddy-permitting models of the North Atlantic, Prog. Oceanog., 48, 123-161, 2001.

C. W. Böning, J. Dengg, and C. Dorow, Institut für Meereskunde, Düsternbrooker Weg 20, 24105, Kiel, Germany. (cboening@ifm.unikiel.de)

M. Rhein, Institut für Umweltphysik, Universität Bremen, Kufsteiner Strasse, NW 1, 28359, Bremen, Germany. (mrhein@physik.uni-bremen.de) 